\title{
A Bioética, seu desenvolvimento e importância para as Ciências da Vida e da Saúde*
}

\author{
Bioethics, her development and importance for the Sciences of Life and Health
}

Fermin Roland Schramm

*Apresentado no I Encontro de Ética em Pesquisa em Seres Humanos: Avanços e D esafios Bioéticos. IN CA/H Cl, Auditório M oacyr Santos Silva, Praça Cruz Vermelha 23, Centro - RJ, 27 de setembro de 2002.

PhD, Pesquisador Associado EN SP-FIOCRUZ e Consultor de Bioética do IN CA. Presidente da Sociedade de Bioética do

Estado do Rio de Janeiro.

Recebido em novembro de 2002.

\section{INTRO DUÇÃO}

Pode-se dizer, sem exageros, que a bioética, amplamente entendida, foi, e continua sendo, a área mais dinâmica e produtiva das éticas aplicadas, como bem mostram 0 site do Kennedy Institute of Ethics da Georgetown U niversity e seus links. ${ }^{1}$

Tal desenvolvimento constitui ao mesmo tempo uma vantagem e uma desvantagem.

Com efeito, em aproximadamente três décadas de pesquisa e atuações práticas, a bioética produziu, mundo afora, uma grande quantidade de especialistas, graduados e pósgraduados; consultores e membros de conselhos e comitês; resoluções e leis, tanto nacionais como internacionais; artigos, livros, revistas, enciclopédias e sites; conferências e comunicações em congressos, simpósios e jornadas. Isso constitui certamente um aspecto positivo, pois é indicio de que a bioética responde a uma necessidade social de dar sentido moral à multiplicidade das práticas humanas, sem 0 qual tais práticas parecem destinadas à confusão da anomia.

M as, o próprio desenvolvimento rápido e intenso da bioética fez com que, hoje, nenhum bioeticista honesto possa afirmar conhecer, em detalhes, todo o campo de sua especialidade. Esta condição de relativa ignorância pode ser interpretada como fonte de frustração perante a multiplicidade irredutível dos dialetos e idioletos bioéticos, ${ }^{2}$ sintetizada pelo mito das Torres de Babel, que, segundo a interpretação dada por Jacques D errida, nos fala ao mesmo tempo da "inadequação de uma língua a outra, de um lugar da enciclopédia a outro, da linguagem a ela mesma e ao sentido" e da necessidade "da tradução inadequada para suprir aquilo que a multiplicidade nos interdiz". ${ }^{3}$

A seguir, apresentarei, em grandes linhas, a bioética, seu desenvolvimento e sua possível utilidade para enfrentar os problemas que se colocam à pesquisa que envolve seres humanos, tendo em conta simultaneamente as exigências disciplinares e metodológicas da bioética e algumas das necessidades da ética em pesquisa da própria instituição que é o INCA.

\section{A BIO ÉTICA NO CONTEXTO DO S DESAFIO S DA CULTURA CONTEMPO RÂNEA}

A bioética é um produto típico da cultura da segunda metade do século XX, pois deve enfrentar pelo menos três dentre os principais desafios da cultura contemporânea, a saber: - a complexidade dos fenômenos a serem analisados - inclusive de muitos daqueles considerados por muito tempo como simples antes que o paradigma quântico veio demonstrar o contexto de incerteza em que se dão nossos saberes; ${ }^{4}$

- a procura deum método - indicado pelostermos "interdisciplinaridade" e "transdisciplinaridade"

- supostamente capaz de superar a fratura 
entre as "duas culturas" (a científica e a humanística), ${ }^{5}$ estabelecer uma "nova aliança" entre elas ${ }^{6}$ e, de forma mais geral, construir os vínculos entre os conhecimentos especializados pertinentes e o contexto em que se produzem a fim de produzir novas possibilidades de conhecimento; ${ }^{7}$

- a preocupação com a aplicabilidade dos saberes sem perder de vista a produtividade da teoria, considerando que esta é normalmente considerada uma preocupação pertencente tão somente à assim chamada pesquisa básica, mas que, de fato, interage e retroage sobre o fazer técnico, da mesma maneira como este retroage sobre aquela. ${ }^{8}$

A bioética, amplamente entendida, se insere nessa complexidade do mundo, nos debates metodológicos sobre disciplinaridade ou interdisciplinaridade (a bioética é uma disciplina ou um campo interdisciplinar?) e nas discussões sobre o tipo de racionalidade (razão teórica ou razão prática?) que fundamenta ou legitima a argumentação moral e os procedimentos que visam à solução de conflitos.

Em outros termos, a bioética se inscreve num contexto no qual devem coabitar as estruturas conflitivas da realidade humana e as tentativas de construir convergências de soluções, consideradas eqüidistantes tanto do dogmatismo quanto do relativismo cético. ${ }^{9}$ Em suma, a bioética pode ser considerada a forma de ética aplicada que mais representa a condição humana contemporânea por dizer respeito aos principais conflitos que surgem nas práticas que envolvem o mundo vivido (Lebenswelt) e às tentativas de dar conta deles. É nesse sentido que se pode também afirmar - talvez de maneira um pouco exagerada - que, referida à condição humana contemporânea, "toda ética é, antes uma bioética". ${ }^{10}$

\section{A NATUREZA E O PAPEL DA BIOÉTICA}

U tilizo a expressão "bioética amplamente entendida", porque atual mente existem muitas concepções diferentes e, em princípio, legítimas de bioética, que vão desde aquela quea entendestricto sensu como ética referida às ações humanas que podem ter efeitos negativos duradouros sobre homens e mulheres, até aquela lato sensu que a entende como uma ética planetária, isto é, como ética preocupada com a responsabilidade, a médio e longo prazo, pelos efeitos daninhos que podem resultar dos atos humanos sobre a vida humana individual, a vida social e cultural, a biosfera e a ecosfera como um todo (esta é, por exemplo, a concepção do teólogo Leonardo Boff). ${ }^{11}$

Entre a concepção stricto sensu e a lato sensu existe toda uma série de concepções intermediárias, que são também coerentes e legítimas do que é a bioética. $N$ ão só sobre quais são - ou deveriam ser - os conceitos, as teorias, os métodos e as estratégias da bioética, mas também sobre qual é - ou deveria ser - a extensão de seu campo de aplicação e atuação.

$\mathrm{No}$ entanto, mesmo aceitando uma concepção "ampliada" de bioética, pode-se afirmar que algumas concepções são implausíveis, como aquela que define a bioética como "ética da vida". Com efeito, esta definição é pelo menos redundante visto que, por definição, a ética se refere sempre às ações dos humanos (que são seres vivos ou sistemas autopoiéticos e irreversíveis) sobre seres e entes vivos (que podem ser humanos ou não e são também sistemas autopoiéticos e irreversíveis).

Dito de maneira mais precisa, a ética, entendida como "tematização reflexiva do ethos", ${ }^{12}$ ou discurso de segunda ordem sobre 0 ethos (palavra grega que pode significar "guarita" para proteger animais e humanos, "costume" que regula a vida em comum dos humanos e "caráter" do agente moral), é uma disciplina filosófica prática que visa a esclarecer e resolver os problemas morais que surgem na práxis humana (que se referea ações sobre outros seres e entes vivos e é distinta da poiesis, ou fabricação de objetos). Portanto, a ética tem sempre a ver com alguma qualidade da relação entre um eu vivo humano, chamado agente moral, e um outro, também vivo, que pode ser um outro agente moral ou um paciente moral, sendo que tanto agentes como pacientes são necessariamente seres vivos. ${ }^{13}$ Por isso, a concepção de bioética como "ética da vida" é praticamente inútil por ser genérica demais e porque não especifica quais são as características pertinentes da vida que a bioética deve 
considerar para se tornar uma ferramenta conceitualmente rigorosa e operacional.

$M$ as existe uma outra razão que torna esta definição de bioética implausível, ou até absurda. Com efeito, adotando-a, o bioeticista setornaria uma espécie de tuttologo (literalmente "especialista em tudo", conforme a expressão do historiador italiano C arlo G inzburg), ${ }^{14}$ isto é, um especialista que, paradoxalmente, deveria conhecer o todo da vida para tornar-se especialista. Evidentemente, esta concepção é inutilizável, pois ninguém conhece 0 "todo", nem 0 "todo" de alguma coisa e, sobretudo, porque, ao referir-se ao "todo" da vida perde-se o verdadeiro foco da bioética, que é a qualidade das práticas humanas sobre os fenômenos vitais e, dentre esses, sobre o fenômeno da vida humana.

Para evitar este tipo de problemas, prefere se dizer que a bioética é a "ética da qualidade da vida" (concepção adotada pela maioria dos assim chamados bioeticistas laicos) ou a "ética da sacralidade da vida" (adotada prevalentemente pelos bioeticistas de inspiração religiosa, em particular, pelos bioeticistas católicos). M as essas definições, embora menos genéricas que a primeira, têm também seus limites, pois Ihe falta ainda dizer o que é "qualidade" e "sacralidade".

Q uem defende uma postura laica de bioética está evidentemente mais próximo da "ética da qualidade da vida" do que da "ética da sacralidade da vida", mas pode-se reconhecer também que na época de crescente objetivação dos seres vivos pela técnica e pelas biotecnologias em nome do bem-estar (quase sempre tão só humano e poucas vezes para todos os humanos), surgem sérios questionamentos éticos, como bem sabem todos aqueles que atuam nos Comitês de Ética em Pesquisa.

Com efeito, esses profissionais têm, dentre outras funções, aquela de proteger os sujeitos humanos que se tornam objetos de pesquisa. Este é, a meu ver, o sentido profundo da preocupação, inscrita na Resolução 196/96 do M inistério da Saúde e seguintes, para com indivíduos e populações ditas "vulneráveis", com a ponderação de riscos e benefícios, com os procedimentos pelos quais se obtém 0 consentimento livre e esclarecido dos sujeitos que se tornam objetos de uma pesquisa.

A relação entre "sacralidade" e "qualidade" é muito mais problemática do que se imagina, pois existe um número importante de pensadores que questiona a legitimidade das intervenções técnicas sobre a "vida nua" e que buscam os meios para tentar protegêla. ${ }^{15}$

Já no outro extremo do espectro das definições de bioética, existem concepções que podem ser consideradas reducionistas. Este é o caso, por exemplo, da concepção que identifica a bioética com a ética médica, baseada nos princípios hipocráticos da não maleficência e da beneficência, e em algumas regras de etiqueta que regulam as relações entre colegas de profissão. Esta concepção, essencialmente deontológica e, no fundo, corporativa, esquece que as éticas aplicadas e a bioética não se reduzem a uma adaptação das antigas deontologias, mas que se preocupam também com questões teleológicas, isto é, com as conseqüências dos atos sobre os sujeitos que são objetos de suas práticas; com a dignidade e o exercício da autonomia individual; com a justiça e a eqüidade. De fato, as éticas aplicadas e a bioética surgem exatamente como resposta às insuficiências das éticas tradicionais, as quais, quando não estavam confundidas com preceitos religiosos e baseadas mais na fé do que na razão, se reduziam a códigos profissionais (como é o caso do "código de ética médica"). Por esta razão não podem dar conta dos novos desafios trazidos, por exemplo, pela emergência de uma cultura da autonomia individual; pelos avanços das tecnociências da vida, da saúdee do ambiente; pelo surgimento dos movimentos sociais dos anos 60, dentre os quais se destacaram 0 movimento dos consumidores e o movimento contra a injustiça e a exclusão; pela emergência daquela que o filósofo italiano $\mathrm{N}$ orberto Bobbio chamou "a era dos direitos". ${ }^{16}$

Portanto, se descartarmos os dois extremos do espectro das concepções de bioética, que podemos considerar inúteis - a primeira pela sua genericidade, a segunda pelo seu reducionismo - e se tentarmos enfrentar a complexidade dos conflitos que afligem nossa época, parece sobrar um espaço do meio, ao mesmo tempo suficientemente abrangente 
(para evitar as idiossincrasias do especialismo descontextualizado) e pertinentemente delimitado (para evitar a generalidade dos "tuttologos", estigmatizados por G inzburg).

Q ual seria esta concepção de bioética razoável para dar conta dos desafios do presente e, eventualmente, de um futuro próximo; isto é, de um futuro ao alcance de um olhar contemporâneo informado e responsável? $\mathrm{Ou}$, dito melhor - e aproximando-nos daquelas que pressuponho ser as preocupações deste Encontro de Ética em Pesquisa do Instituto $\mathrm{N}$ acional de $\mathrm{C}$ âncer (IN CA): qual poderia ser a identidade que se pode razoavelmente atribuir à bioética - dentre aquelas já existentes - para que a bioética possa ser considerada ao mesmo tempo conceitualmente coerente e rigorosa e operacional, ou seja, adaptada aos problemas morais que uma instituição complexa, com as características como são aquelas do IN CA, deve enfrentar?

Penso que a complexidade desta instituição requer uma concepção de bioética que seja suficientemente abrangente também razoavelmente adaptada à situação em que a pesquisa e a prática médica em 0 ncologia devem atuar. Por isso, penso também que deva tratar-se de uma ferramenta teórica e prática que contemple as tarefas de:

(a) entender os conflitos;

(b) fazer convergir as soluções propostas (e, quando possível, integrá-las); e

(c) proteger os indivíduos e as populações envolvidas.

Considero esta definição de bioética "amplamente entendida" razoavelmente operacional para enfrentar os problemas em que a pesquisa em 0 ncologia se insere.

Com efeito, enquanto órgão do M inistério da Saúde (M S), mas também como H ospital que atende de facto boa parte da população in loco (e sem entrar no mérito de saber se também deve ou não atendê-la), o IN CA enfrenta um tríplice desafio.

Em primeiro lugar, deve subsidiar o MS em formular políticas de assistência aos portadores de doenças oncológicas, ao mesmo tempo suficientemente universais e eficientemente integrais, como requerido tanto pelaC onstituição quanto pelas diretrizes do SUS. I sso implica em formular políticas públicas eticamente sustentáveis e operacionalmente razoáveis, o que pode ser obtido, por exemplo, graças aos trabalhos do ConBio-INCA.

$M$ as isso implica inevitavelmente em ter que enfrentar um segundo desafio, que consiste em equacionar a extensão da cobertura e a quantidade e qualidade de procedimentos disponíveis para os indivíduos, portadores de neoplasias, que precisam ser assistidos em sua vulnerabilidade e desamparo. Além de ter que "barganhar" com outras instâncias, que defendem interesses e valores igualmente "justos" (se considerarmos o contexto de numa sociedade a princípio democrática e pluralista como é a brasileira) e tidos como indispensáveis a uma vida razoavelmente digna, tais como o exercício responsável da autonomia pessoal; 0 acesso à informação, à cultura eà educação (para poder viver como seres autenticamente "simbólicos" e não unicamente como respeitáveis mamíferos); 0 direito à segurança pessoal (para que cada membro da comunidade humana possa viver e não somente sobreviver graças à "força bruta"); o reconhecimento recíproco (para darmos conta que o "outro" é o que permite ao "eu" ter uma vida de relação); 0 direito aos afetos e ao amor (para esquecermos, embora por pouco tempo, de que somos finitos e mortais); o direito a uma saudável dialética entre competição e cooperação, dentre outros bens.

Em outros termos - como nos ensinou 0 filósofo norte-americano M ichael Walzer ${ }^{17}$ quando temos que enfrentar a questão sanitária, do ponto da justiça distributiva e preocupados em respeitar a real complexidade que as sociedades contemporâneas adquiriram historicamente, devemos também enfrentar o desafio de reconhecer que, para as pessoas humanas, existem várias esferas legítimas de justiça, cada uma contendo um bem considerado fundamental, não redutível aos outros. É este o sentido do pluralismo democrático contemporâneo, o qual implica que não existenenhum bem fundamental que possa ser considerado como aquele que teria uma prioridade lexical (quer dizer a priori) sobre os demais, independentemente das contingências históricas e existenciais.

Por fim, existe um terceiro desafio, que 
consiste em implementar políticas protetoras capazes de integrar, do ponto de vista da cobertura em 0 ncologia, 0 vasto território constituído pelos "vários Brasis" existentes. O começo desta política sanitária protetora parece ser representado pelo projeto Expande.

Penso que qualquer Comitê de Ética em Pesquisa tem também, mutatis mutandis, esses três tipos de desafios, a saber: analisar e entender os conflitos de interesses e valores que uma pesquisa com seres humanos necessariamente envolve; tentar prescrever as melhores soluções (ou pelo menos as menos ruins) para que tais conflitos sejam enfrentados e solucionados, preocupando-se portanto com a convergência entre propostas para se chegar a acordos razoáveis; propiciar meios de proteção aos envolvidos pela pesquisa, sabendo que a vulnerabilidade não é só uma condição dos pesquisados, mas pode ser também dos próprios pesquisadores que atuam num meio caracterizado por conflitos de interesses muitas vezes poderosos.

\section{O DESENVO LVIMENTO DA BIO ÉTICA}

Como vimos, a bioética, enquanto ética aplicada, pode ser considerada atualmente como uma "ferramenta" ao mesmo tempo conceitual e pragmática, quer dizer, ao serviço seja da análise seja da resolução dos conflitos e dilemas morais que surgem com as práticas no campo das aplicações das Ciências da Vida e da Saúde. $M$ ais precisamente: a bioética é a tematização do ethos, tendo em conta as práticas humanas que podem ter efeitos irreversíveis sobre outros humanos, os seres vivos em geral e 0 ambiente natural. ${ }^{18}$

Com este sentido amplo, a bioética surgiu, nominalmente, no campo da O ncologia, quando o bioquímico norte-americano Van Rensselaer Potter (1911-2001), pesquisador em O ncologia, criou o neologismo bioethics, partindo de uma analogia: a de que os humanos estariam agindo sobre 0 mundo natural da mesma maneira como as células cancerígenas agem sobre o organismo humano. ${ }^{19}$ I ntenção do pesquisador - leitor das obras de Aldo Leopold e M argareth $M$ ead sobre o futuro da humanidade e sensibilizado pelas reivindicações do movimento ecologista sobre a qualidade da vida ${ }^{20}$ - era a de indicar uma nova disciplina (mais exatamente: um novo campo interdisciplinar), que indicara pela metáfora de "ponte para o futuro", que chamou de "ciência da sobrevivência humana" e que deveria situar-se na interface entre os "fatos" das ciências biológicas, amplamente entendidas, e "os valores" das ciências humanas. ${ }^{21}$

No entanto, a concepção de Potter ficou minoritária no panorama das várias concepções existentes durante praticamente duas décadas (anos 70-80). Durante este período só teve uma certa influência na assim chamada ética ambiental (considerada por muitos pesquisadores como distinta e diferente da bioética), voltando a ocupar um papel importante no cenário bioético mundial na época do IV Congresso M undial da IAB no Japão (1998), quando a bioética já vinha se preocupando com as implicações morais da G lobalização. 22,23 Isso se deve, em parte, a problemas teóricos detectados tanto na primeira formulação, que considerava a bioética uma nova ética científica, quanto na posterior reformulação em termos de "bioética global" (como o próprio autor rebatizou sua concepção anterior em 1988) ${ }^{24}$ e, em parte, a problemas operacionais. Com efeito, não ficava claro como articular cultura científica e cultura humanista, ou seja, como produzir uma ferramenta coerente e consistente para analisar conflitos e prescrever comportamentos corretos em âmbitos tão diferentes como o encontro clínico, as políticas sanitárias, a pesquisa com seres humanos, a pesquisa com animais nãohumanos, a engenharia genética, as intervenções no ambiente.

Por isso, durante os anos 70 e 80 surgiram e se afirmaram várias concepções concorrentes. N os Estados Unidos e, em geral, nos países de língua inglesa: aquela, majoritária, desenvolvida pelos pesquisadores do Kennedy Institute da Georgetown U niversity, e conhecida como principialismo; ${ }^{25}$ a ética prática, de inspiração utilitarista, desenvolvida sobretudo por Peter Singer; a reatualização da tradicional casuística; e ética das virtudes; o libertarianismo; a ética dos cuidados; o comunitarismo, dentre outras correntes. $\mathrm{N} \mathrm{a}$ Europa: o personalismo (sobretudo na área 
de língua francesa); a hermenêutica; a ética narrativa e a ética discursiva de língua alemã, dentre outras.

No Brasil, a bioética surge na segunda metade dos anos 80 . Por ser uma "bioética tardia" (como afirma 0 atual presidente da Sociedade Brasileira de Bioética Volnei Garrafa), ela goza de uma relativa liberdade com relação às várias tradições existentes no mercado internacional. No começo, ela se divide entre os defensores da corrente principialista norte-americana e aquela que podemos chamar de "bioética da saúde pública", que é uma tentativa de construir um corpus conceitual específico, adaptado à situação sanitária brasileira. ${ }^{26-28} \mathrm{Já}$ em meados dos anos 90, a bioética brasileira integra as várias correntes da bioética mundial, desenvolve-se sobretudo graças à criação, em 1996, do sistema CON EP-CEP, num típico processo criativo de "antropofagia cultural" ${ }^{29}$ Já na passagem do M ilênio, sempre continuando a coexistirem as referências às várias tendências mundiais, acrescentam-se duas novas tendências, originadas sobretudo pela reflexão sobre a saúde pública: uma bioética de intervenção social, chamada pelo seu formulador Volnei G arrafa de "bioética dura" e uma "bioética da proteção", desenvolvida, conjuntamente, pelo escrevente e o bioeticista chileno Miguel Kottow.

\section{CONCLUSÃO}

É possível que a medicina tenha, provisoriamente, salvado a vida à ética (como afirmara o eticista Stephen Toulmin), ${ }^{30}$ tirando-a das meras abstrações formais da metaética vigente durante a primeira metade do século XX, devido sobretudo ao domínio da corrente analítica e do neopositivismo no campo da filosofia moral. O principal resultado desse processo é o surgimento das éticas aplicadas e da bioética, que, sem renegar os aportes fundamentais da filosofia analítica em termos de rigor metodológico, imprimiram uma segunda guinada ao desenvolvimento da ética do século XX: a guinada neopragmática (a primeira sendo a guinada lingüística da primeira metade do século), preocupada não somente com a forma e o conteúdo da racionalidade ética nas análises dos conflitos morais que surgem das práticas no campo das Ciências da Vida e da Saúde, mas também com os efeitos pragmáticos das tomadas de decisão que afetam a qualidade de vida de indivíduos e populações humanas.

$\mathrm{N}$ este sentido, pode-se completar a afirmação de Toulmin, afirmando que a ética aplicada e a bioética estão reconfigurando a maneira como as práticas nas Ciências da Vida e da Saúde devem lidar com os pacientes no encontro clínico; com os sujeitos, objetos de pesquisa; com os indivíduos e as populações humanas a serem protegidos pelas políticas públicas de saúde.

Sendo assim, a bioética pode ser vista também como o que pode salvar a vida moral da Medicina, sendo que ela permite outrossim encarar muitos dos desafios implicados pelas práticas das C iências da V ida e da Saúde, em particular, pelas pesquisas que envolvem seres humanos.

\section{REFERÊN CIAS BIBLIO G RÁFICAS}

1. Georgetown University. Kennedy Institute of Ethics(US). Availablefrom:

http://www.bioethics. georgetown.edu

2. GarrafaV, D iniz D, Guilhem D B. Bioethical language and its dialects and idiolects. $\mathrm{C}$ ad Saúde Pública 1999;15(1):35-42.

3. D errida J. Torres de Babel. Belo H orizonte: UFM G; 2002. p.11.

4. H eisenbergW. D iephysicalischen prinzipien der quantentheorie. Leipzig: Hirzel Verlag; 1930.

5. Snow CP. The two cultures. London: Cambridge U niversity Press; 1959.

6. Prigogine I, Stengers I. La nouvelle alliance: métamorphoses dela science. Paris: G allimard; 1979.

7. Ceruti M. II vincolo e la posibilita. M ilano: Feltrinelli; 1989.

8. M orin E. La méthode. Lesidées. Leur habitat, leur vie, leur moeurs, leur organisation. Paris: Editions du Seuil; 1991.

9. M aliandi R. Laéticacuestionada. Prolegómenos paraunaética convergente. BuenosAires: Editorial Almagesto; 1998. p. 5-7.

10. Schramm FR. Todaéticaé, antes, uma bioética. H umanidades 1994;9(4):324-31. 
11. Boff L. D o icebergàA Arca deN oé: o nascimento de uma ética planetária. Rio de Janeiro: Garamond; 2002.

12. M aliandi R, op. cit., p. 48.

13. Kottow M . Introducción a la bioética. Santiago: Editorial U niversitaria; 1995. p. 52.

14. Carvalho FrançaJ M . 0 historiador globalizado. Folha deSão Paulo 1 set 2002;M ais:4-8.

15. Agamben G. H omo sacer: o poder soberano ea vidanual. Belo H orizonte: U FM G ; 2002.

16. Bobbio N . A era dos direitos. Rio de Janeiro: Campus; 1992.

17. Walzer M . Spheres of justice: a defense of pluralism and equality. N ew York: Basic Books; 1983.

18. Kottow M . Introducción ala bioética. Santiago: Editorial U niversitaria; 1995. p. 53.

19. PotterVR. Bioethics, science of survival. Perspect Biol M ed 1970;14:127-53.

20. Schramm FR. N iilismo tecnocientífico, holismo moral ea "bioética global" deVR Potter. $\mathrm{H}$ ist Ciênc Saúde 1997;4(1):95-115.

21. Potter VR. Bioethics: bridge to the future. Englewood Cliffs: PrenticeH all; 1971.
22. Campbell AV. Presidential address: global bioethics: dream or nightmare? Bioethics 1999;13(3/4):183-90.

23. Sakamoto H . Towards a new "global bioethics". Bioethics 1999;13(3/4):191-7.

24. Potter V R. G lobal bioethics: building on the Leopold Legacy. East Lansing: M ichigan State U niversity Press; 1988.

25. Beauchamp T L, Childress]. Principles of biomedical ethics. Oxford: Oxford U niversity Press; 1979.

26. G arrafaV. A dimensão ética em saúde pública. São Paulo: FSPUSP; 1995.

27. Schramm FR. A terceira margem da saúde: ética natural, complexidade, criseeresponsabilidade no saber-fazer sanitário. Braślia: U nB; 1996.

28. Schramm FR. D a bioética "privada" à bioética "pública". In: Fleury S, organizador. Saúdee democracia: aluta do CEBES. São Paulo: Ed. Lemos; 1997. p. 227-40.

29. Schramm FR. A bioéticano Brasil entreo antigo eo novo. Cad Adenauer 2002;3(1):87-101.

30. Toulmin S. H ow medicinesaved thelife of ethics. Perspect Biol M ed 1983;25:736-50. 